\title{
Reliability of histopathological examination and immunohistochemistry of a single biopsy for evaluation of endometrial health in Icelandic mares
}

\author{
Monika Sikora ${ }^{1}$, Marcin Nowak ${ }^{2}$, Henryk Racheniuk ${ }^{3}$, \\ Katarzyna Wojtysiak ${ }^{1}$, Roland Kozdrowski ${ }^{1}$
}

${ }^{1}$ Department of Reproduction and Clinic of Farm Animals, Faculty of Veterinary Medicine, Wroclaw University of Environmental and Life Sciences, Wroclaw, Poland

${ }^{2}$ Department of Pathology, Faculty of Veterinary Medicine, Wroclaw University of Environmental and Life Sciences, Wroclaw, Poland

${ }^{3}$ Institute of Physiotherapy, Faculty of Physiotherapy and Physical Education, Opole University of Technology, Opole, Poland

\begin{abstract}
Introduction. Endometritis and endometrosis have been and still are the major reasons for infertility in mares. The diagnosis of endometritis can be based on cytology and microbiology, but endometrial biopsy is still the only way to diagnose endometrosis in the mare. Our study attempted to determine if a single biopsy using histopathology and immunohistochemistry is sufficient to ascertain reasons for infertility in Icelandic mares. The objectives of this study were to examine the relationship between deviations in endometrial biopsies in terms of prostaglandin-endoperoxide synthase-2 (PTGS-2) and fibronectin expression and polymorphonuclear cells (PMNs) infiltration, as well as scoring degeneration in two endometrial biopsies.

Material and methods. Materials were collected from 53 Icelandic breed mares, from whom two endometrial biopsies were collected and they were used for histopathology and for immunohistochemistry for PTGS-2 and fibronectin.

Results. In our study, twenty-six of 53 mares (49\%) showed differences in the biopsy score between the left and the right uterine horns $(\mathrm{p}=0.002)$. There were statistically significant differences in fibronectin expression $(\mathrm{p}=0.001)$, as well as in PTGS-2 expression in the superficial epithelium $(\mathrm{p}=0.017)$.

Conclusions. Significant differences in the biopsy score, and fibronectin and PTGS-2 expression, between two endometrial biopsies obtained from individual mares demonstrated that a single biopsy could be insufficient for diagnosing uterine health status in Icelandic mares. (Folia Histochemica et Cytobiologica 2017, Vol. 55, No. 3, 168-175)
\end{abstract}

Key words: mare; infertility; endometritis; histopathology; fibronectin; prostaglandin-endoperoxide synthase-2; IHC

Correspondence address: $\mathrm{M}$. Sikora

Department of Reproduction and Clinic of Farm Animals

Faculty of Veterinary Medicine

Wroclaw University of Environmental and Life Sciences

Plac Grunwaldzki 49, 50-366 Wroclaw, Poland

e-mail: monika.sikora88@gmail.com

\section{Introduction}

Endometritis and endometrosis have been and still are the major reasons for infertility in mares [1, 2]. Traub-Dargatz et al. [3] stated that endometritis is the third most significant clinical problem in horses after colic and respiratory diseases. The diagnosis of infertility can be based on several approaches, such as history, clinical findings and transrectal and ultrasono- 
graphic evaluation of the genital tract, and additional assessments. While the diagnosis of endometritis can be based on cytology and microbiology, endometrosis can only be diagnosed by evaluation of endometrial biopsies (EB) [1]. Histopathological examination of EB has been and continues to be internationally recognized as the best tool for diagnosing infertility and for prognostic evaluation of endometrial pathologies [4]. It has been described as a reliable, meaningful and risk-free method for diagnosing endometritis and as a valuable tool for determining treatment success $[5,6]$. However, the long waiting time needed for histopathological results makes it impossible to apply treatment immediately after sampling [7-9].

Alternatively, a small portion of endometrium, obtained by biopsy and smeared onto a sterile microscope glass, can be used for cytological analysis and provides rapid results. Kozdrowski et al. [10] examined the relationship between polymorphonuclear cells (PMNs) infiltration in the endometrial luminal epithelium and stratum compactum and the presence of PMNs in cytological specimens made using EB and cytobrush (CB). They observed that relationship was always higher in samples obtained by EB than those obtained by CB. While cytology obtained from EB provides quick results, the detection of PMNs in histopathological examination is considered as 'the best standard' for diagnosis of endometritis [11]. Furthermore, classification of degenerative changes of the endometrium into the appropriate grading score according to Kenney and Doig [12] allows estimation of the prognosis for fertility of mares. Endometrosis in horses is described as a multifactorial, progressive process involving formation of fibrotic and dilated glands or glandular nests, and atrophy or hypertrophy of the epithelium, associated with periglandular and/ /or stromal fibrosis [1, 13-15]. It has been reported that the affected glands differentiate irregularly during the estrous cycle [5].

Fibronectin, an extracellular matrix (ECM) protein, is responsible for stromal cell adhesion to the interstitial matrix [16]. The ECM is a dynamic, elastic and multicomponent structure that fills the spaces between cells, provides a storage site for growth factors and cytokines [16]. The endometrial ECM and the basement membrane play important roles in embryo implantation, trophoblast cell invasion of the decidualized endometrium and the maintenance of gestation [17]. In cows ECM undergoes cyclic remodeling [18, 19]. Walter et al. [1] hypothesized that similar processes occur in the equine endometrium. In the same study it was reported that fibronectin was presented in highly fibrotic regions of the equine endometrium [1].
In the endometrium of mares, the synthesis of prostaglandin is preceded by modulation of prostaglandin-endoperoxide synthase-2 (PTGS-2) expression [20]. PTGS-2 is a $72 \mathrm{kDa}$ protein that is responsible for the biosynthesis of prostaglandins under acute inflammatory conditions [21]. Boerboom et al. reported that PTGS-2 and prostaglandin-F (PGF) synthase are co-localized in epithelial cells of the endometrium, and near to luteolysis there is a positive correlation between the release of $\mathrm{PGF}_{2 \alpha}$ and the expression of endometrial PTGS-2 [20].

Generally, in practice only a single uterine biopsy is collected; however, several authors reported that the diagnosis based on the one sample could be misleading and incomplete [22-24]. Fiala et al. [22] in their study performed after slaughter showed that a single biopsy is not sufficiently accurate to determine the type and severity of inflammation in mares' endometrium. Another post-mortem study revealed that evaluation of inflammation using the presence of PMNs in cytology and histology specimens does not give the same results in different sampling sites [23].

Although the histopathological examination of EB is recognized as 'the gold standard' for diagnosing endometritis, in searching for new approaches, in the present study the expression of PTGS-2 and fibronectin in endometrial biopsies was determined using immunohistochemistry (IHC). The aim of this study was to examine the relationship between deviations in endometrial biopsies in terms of PTGS-2 and fibronectin expression and PMNs infiltration, as well as reproductive status (maiden mare/multiparous mare), age of mares (more than $10 \mathrm{y} /$ less than $10 \mathrm{y}$ ), and scoring of endometrial degeneration according to the Kenney and Doig [12] grading system in two biopsies from each mare. Our study attempted to determine if a single biopsy is sufficient or not to diagnose causes of infertility using histopathology and IHC.

\section{Material and methods}

Animals. The study was conducted on 53 Icelandic Horse mares, aged from 3 to 25 years $(12.34 \pm 5.72$ years, mean $\pm \mathrm{SD})$, which were classified for the study as described by Sikora et al. [24]. This study was approved by Icelandic Food and Veterinary Authority with a reference number of approval 2014-01-04. The animals were handled according to good ethical standards.

Briefly, all samples were collected from mares with a history of infertility during one breeding season from May to August 2014 in Iceland. They were qualified for the study based on the following criteria: they had been bred three or more times unsuccessfully in the same breeding season, or had a history of a minimum of one year's reproductive 
failure. All of the mares were examined while restrained in stocks. The sample collections were performed after a complete reproductive assessment of the horses, including evaluation of the external genitalia and manual transrectal palpation, as well as ultrasonographic examinations (GE Logiq Book XP, Fairfield, NY, USA) of the reproductive tract to determine cycle stage and to exclude presence of intrauterine fluid. In the ultrasound examination of the reproductive tract, all the mares were in estrus and they showed no intrauterine fluid. Moreover, no discharge from the vagina was apparent and none of the mares was previously treated for endometritis. During examination of the external genitalia, in all mares $80 \%$ of the labial lengths were below the pelvic brim. Afterwards, the tail was bandaged, the vulva and the perineum were cleaned with povidone-iodine (Betadine $^{\circledR}$ - Polyvidonum iodinatum, MEDA Pharma S.p.A., Milan, Italy) and dried with a paper towel. First, an endometrial swab was obtained, then a uterine lavage was performed, and finally two endometrial biopsies from left and right uterine horns were obtained. All the samples were obtained during at the same sampling procedures and that lasted less than $15 \mathrm{~min}$. The endometrial swab (ES) and uterine lavage (UL) were collected for another part of the study, published by Sikora et al. [24]. In this paper the main subject of study is histopathological examination of endometrial biopsies, collected from mares, as well as the assessment of immunohistochemical reactivity of the stroma to antibody against fibronectin and reactivity of the surface and glandular epithelia to antibody against PTGS-2 in the same endometrial biopsies.

Examination of endometrial biopsies. EBs were obtained from the dorsal wall of the base of each uterine horn and fixed in $10 \%$ formalin for histopathological examination. The biopsies were collected using a sterilized biopsy punch (Equi-Vet, Kruuse, Denmark) that was manually passed through the cervix and then directed into the left and right uterine horns with a finger and through rectal manipulation with the other hand. The EB were always collected in the same order: first from the left and then from the right horn.

Endometrial biopsies were fixed in $10 \%$ formalin. After fixation, biopsy samples were embedded in paraffin blocks, cut into $4 \mu \mathrm{m}$-thick sections and stained with hematoxylin-eosin (HE). Evaluation was performed under light microscopy for infiltration by PMN of the endometrial luminal epithelium and the endometrial stratum compactum. Samples were considered positive for acute endometritis if three or more PMN per five view-fields at the total magnification $400 \times$ of Olympus BX53 optical microscope (Olympus, Tokyo, Japan) were found in at least one of the biopsies [25-27]. The counting procedures were performed according to Meuten et al. [28] and the high-power fields used for evaluation were randomly selected.
Next, the same biopsies were also used to evaluate the intensity of PTGS-2 and fibronectin immunohistochemical staining by the streptavidin-biotin-peroxidase method. Formalin-fixed, paraffin-embedded tissues were cut into $4 \mu \mathrm{m}$-thick sections and mounted on Superfrost Plus slides (Menzel Gläser, Braunschweig, Germany). The sections were then dewaxed with xylene and gradually hydrated in an alcohol series. The activity of endogenous peroxidase was blocked by a $5 \mathrm{~min}$ exposure to $3 \% \mathrm{H}_{2} \mathrm{O}_{2}$. The sections were then heated in a microwave oven for $15 \mathrm{~min}$ in an Antigen Retrieval Solution (DakoCytomation, Glostrup, Denmark). In order to measure levels of the antigens studied, the following antibodies were applied, each diluted at 1:100 in phosphate-buffered saline (PBS): Prostaglandin-endoperoxide synthase 2 antibody (Polyclonal Rabbit, cat. No. orb182638, Biorbyt, UK) and fibronectin antibody (Polyclonal Rabbit Antibody, catalogue No. orb221410). After incubation with the primary antibodies for $1 \mathrm{~h}$ at room temperature (RT), the samples were incubated ( $15 \mathrm{~min}, \mathrm{RT}$ ) with secondary biotinylated antibodies and a streptavidin-biotinylated peroxidase complex (LSAB2, HRP, DakoCytomation). The substrate for the reaction (7 min RT) was 3,3'-diaminobenzidine (DakoCytomation). All sections were counterstained with Meyer's hematoxylin. The antibodies were validated for the use in immunohistochemistry on formalin fixed tissues. In all cases, controls were included by substituting the specific antibody with the Primary Negative Control (DakoCytomation). The positive control for the PTGS-2 was horse colon and for fibronectin was horse liver.

The relative staining intensity for immunoreactive fibronectin and PTGS-2 protein expression was assessed visually in endometrial biopsies $(n=2$ per animal $)$ from each mare by two independent observers. Intensity of immunohistochemical labeling was quantified using a subjective score; i.e., (0) no staining, (1) weak staining, (2) moderate staining or (3) strong staining, and an overall score was generated by averaging the scores provided by each researcher.

Microphotographs of all the tissues studied were subjected to a computer-assisted image analysis via a computer coupled to a BX53 optical microscope (Olympus, Tokyo, Japan). The setup had the ability to both record images and analyze them digitally. The measurements were carried out using Cell ${ }^{\mathrm{A}}$ software (Olympus Soft Imaging Solution $\mathrm{GmbH}$, Munster, Germany).

Statistical analysis. Statistical analyses were performed using STATISTICA (StatSoft, Krakow, Poland). A double statistical analysis was used to determine coherency levels among the histomorphological and immunohistochemical results. The correlations between two biopsies collected from the same mare were evaluated using the chi-square test (NW). It is a test of independent chi-square as a function of the highest credibility (most likelihood - ML). The Spearman test was used to evaluate the dependence between 
fibronectin and PTGS-2 expression in left/right uterine horns and 1) the PMNs infiltration, 2) reproductive status (maiden mare/multiparous mare), 3) age of mares (more than $10 \mathrm{y} /$ /less than $10 \mathrm{y}$ ), and 4) biopsy classification according to the Kenney and Doig [12] grading system. The Spearman rank correlation coefficient was designated as follows: $r>0$ positive correlation, $r=0$ no correlation, $r<0$ negative correlation. The positive correlation was divided into 5 categories: $0.0-0.3$ - negligible correlation; $0.3-0.5-$ low correlation; $0.5-0.7$ - moderate correlation; $0.7-0.9-$ high correlation; $0.9-1.0$ - very high correlation. The significance level was set at $\mathrm{p}<0.05$.

\section{Results}

All the individual data of 53 mares under study has been presented in Supplementary Table 1.

\section{Histopathological assessment of endometrial biopsies}

Results of PMNs infiltration were published in a previous study by Sikora et al. [24]. Briefly: PMNs infiltration of the endometrium was present in 25 of 53 mares (47.2\%). Only 10 of the 25 mares with PMNs infiltration of the endometrium (40\%) exhibited an increase of PMNs in both biopsies that were collected from the base of each horn. Fifteen mares $(60 \%)$ had infiltration of PMNs in only one horn (12 mares - left horn, 3 mares — right horn).

The endometrial biopsies stained with HE were categorized according to the Kenney and Doig [12] grading system. The results are presented in Supplementary Table 1 . Forty-four of 53 EBs $(83 \%)$ were classified as normal or having only modest alteration (grade I-I, I-IIA, IIA-IIA) and nine (17\%) were classified as having endometrial degeneration (grade IIA-IIB, IIB-IIB, IIB-III, III-III). Twenty-six of 53 mares $(49 \%)$ showed differences in the biopsy classification according to Kenney and Doig [12] between the left and the right uterine horns, i.e. 16 mares with PMNs infiltration in the endometrium and 10 mares without PMNs infiltration. A significant difference in the Kenney score between the left and right uterine horns was demonstrated (Table 1).

\section{Immunoreactivity of fibronectin and PTGS-2 in endometrial biopsies}

The reactivity of the stroma to antibody against fibronectin, as well as the reactivity of surface and glandular epithelia to antibody against PTGS-2 were classified into weak, moderate and strong staining. Figure 1 presents different staining responses of the stroma to antibody against fibronectin, while Figure 2 presents the immunohistochemical reactivity of
Table 1. Differences between right and left uterine horns in mares' endometrial biopsy classification according to Kenney and Doig [12]

\begin{tabular}{|l|l|c|c|c|c|}
\hline & \multicolumn{5}{|c|}{ Right horn } \\
\hline \multirow{5}{*}{ Left horn } & Grades & I & IIA & IIB & III \\
\cline { 2 - 6 } & I & 14 & 8 & 0 & 0 \\
\cline { 2 - 6 } & IIA & 13 & 9 & 1 & 0 \\
\cline { 2 - 6 } & IIB & 0 & 2 & 3 & 0 \\
\cline { 2 - 6 } & III & 0 & 1 & 1 & 1 \\
\cline { 2 - 6 } & Total number & 27 & 20 & 5 & 1 \\
\hline
\end{tabular}

surface and glandular epithelia to antibody against PTGS-2. We found statistically significant differences between the left and right uterine horns in fibronectin expression in the stroma $(p=0.001)$ (Fig. 1) as well as in PTGS-2 expression in the surface epithelium $(p=0.017)$ (Fig. 2). Statistically significant correlations were found between PTGS-2 expression in the surface epithelium and fibronectin expression in the stroma and PMNs infiltration in the endometrium, as well as with the Kenney and Doig [12] grading system. In our study, principally the expression of fibronectin in the stroma of the mare's endometrium was evaluated, but as it is presented in Figure 1 the fibronectin expression was also identified in the wall of blood vessels (Fig. 1). Positive Spearman correlations were demonstrated between PTGS-2 expression in the surface epithelium, as well as fibronectin expression in the stroma and PMNs infiltration in the endometrium and the Kenney and Doig [12] grading score. All of the correlations are presented in Table 2 .

\section{Discussion}

Generally, histopathological examination of uterine biopsies allows us to assess overall changes in the endometrial tissue, including infiltration by inflammatory cells, as well as to classify the degree of degeneration of the endometrium. Although the classification system of Kenney and Doig [12] is not perfect [30], it is widely used to designate the grade of alterations in equine endometrosis $[4,8,13]$. With endometrosis, some histological changes are associated, such as formation of fibrotic and dilated glands or glandular nests [5] and endometrial biopsy is the only way to diagnose this [1]. The equine endometrium undergoes cyclic remodeling of the connective tissue ECM, like in other species [1], and fibroblastic cells play an important role in pathogenesis of fibrotic processes in the endometrium [31,32]. Krzyzanowska-Golab et al. [16] reported that the ECM undergoes 

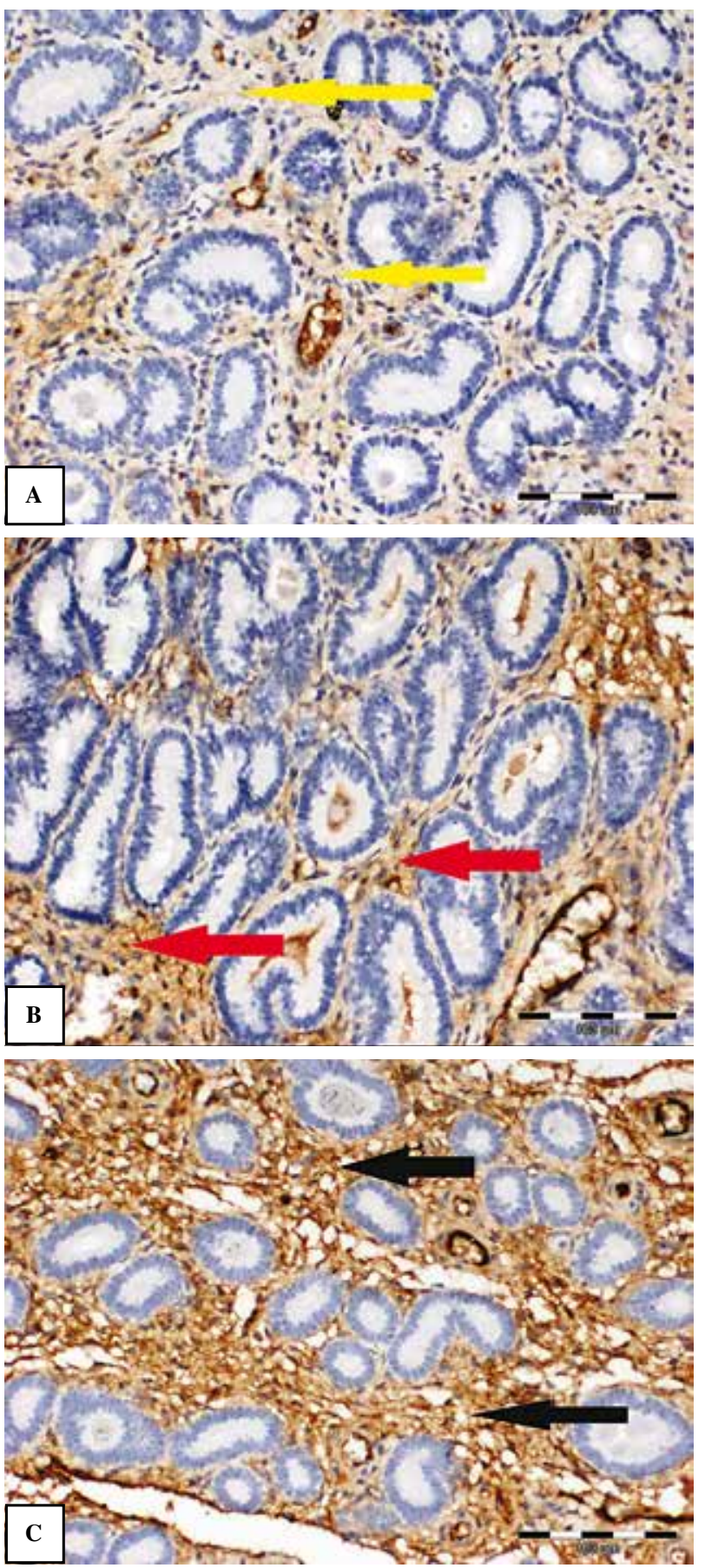

Figure 1. Immunoreactivity of fibronectin in the stroma of infertile mare's endometrium. A. Yellow arrow - weak staining; B. Red arrow - moderate staining; C. Black arrow — strong staining. The immunohistochemical staining was performed as described in Material and methods.

constant remodeling, mostly during repair processes. In the present study, positive Spearman correlations between fibronectin immunolabeling and PMNs infiltration, as well as with the Kenney and Doig [12] grading system were observed. Walter et al. [1] in
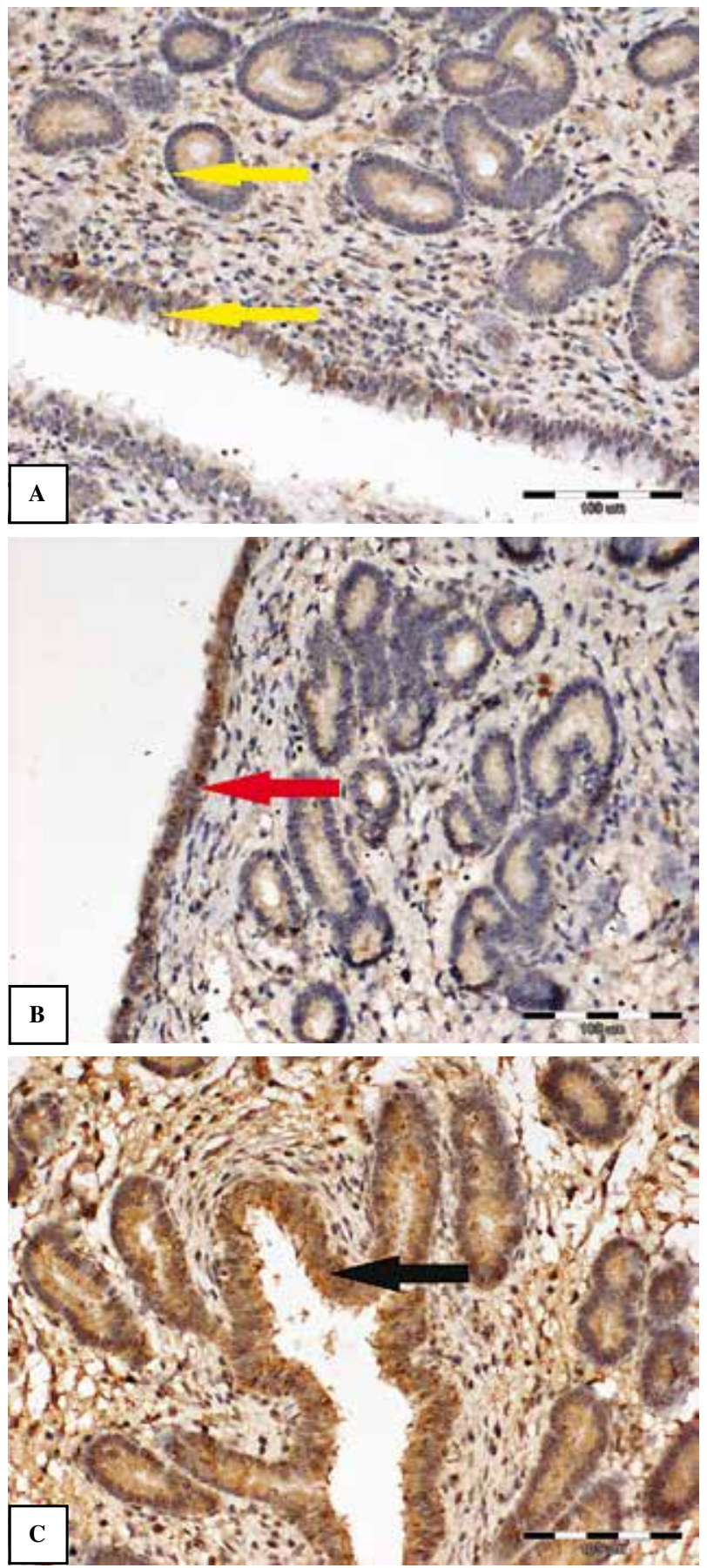

Figure 2. Immunoreactivity of prostaglandin-endoperoxide synthase-2 in the surface and glandular epithelium in infertile mare's endometrium. A. Yellow arrow - weak staining; B. Red arrow - moderate staining; C. Black arrow — strong staining. The immunohistochemical staining was performed as described in Material and methods.

a study carried out on healthy mares observed that fibronectin staining was weak and distributed within the uterine stroma. Hoffmann et al. [14] described that more fibronectin tended to be expressed during active destructive endometrosis than in other types 
Table 2. Spearman rank correlations between prostaglandin-endoperoxide synthase 2 (PTGS-2) and fibronectin (FIBRO) immunoexpression with polymorphonuclear cells (PMNs) infiltration in the endometrium, number of foalings, age of mares and the Kenney and Doig [12] grading system

\begin{tabular}{|l|l|c|c|c|c|c|}
\hline \multicolumn{2}{|l}{} & $\begin{array}{c}\text { PMNs infiltration in } \\
\text { the endometrium }\end{array}$ & $\begin{array}{c}\text { Number of } \\
\text { foalings }\end{array}$ & $\begin{array}{c}\text { Age of mares } \\
\text { Kenney and Doig } \\
\text { grading system }\end{array}$ \\
\hline \multirow{3}{*}{ PTGS-2 } & \multirow{2}{*}{ Surface epithelium } & LH & $0.285^{\wedge}$ & 0.017 & -0.066 & $0.49^{\wedge}$ \\
\cline { 2 - 7 } & \multirow{2}{*}{ Glandular epithelium } & RH & $0.283^{\wedge}$ & $0.289^{\wedge}$ & -0.094 & $0.7^{\wedge}$ \\
\cline { 3 - 7 } & LH & 0.135 & -0.065 & 0.04 & 0.203 \\
\hline \multirow{2}{*}{ FIBRO } & \multirow{2}{*}{ Stroma } & RH & 0.058 & $0.361^{\wedge}$ & 0.164 & 0.211 \\
\cline { 3 - 8 } & & LH & $0.31^{\wedge}$ & 0.173 & 0.124 & $0.41^{\wedge}$ \\
\hline
\end{tabular}

a Based on data published in [24]. Abbreviations: $\mathrm{LH}$ - left horn; $\mathrm{RH}$ - right horn; $\wedge$ p $<0.05$.

of endometrosis. Hoffmann et al. [14] concluded that this is probably due to an increased number of actively secretory myofibroblasts. In this study, weak immunoreactivity for fibronectin in the stroma was associated with scores I and IIA in the grading system of Kenney and Doig [12]. Multiparous mares older than 10 years, with endometrial biopsies having scores IIB/III in at least one biopsy sample, showed moderate to strong immunoreactivity for fibronectin in the endometrial stroma. Mansour et al. [33] in a study on healthy mares observed that fibronectin was identified in the interstitium and blood vessels of the endometrium, but they did not find differences in immunolabeling among samples obtained from different stages of the estrous cycle. In the present study the fibronectin expression was also observed in blood vessels of the endometrium. All of the mares in our study were in estrus at the time of sample collection and had the same history of infertility.

To our knowledge, there are no reports about the causes of increased PTGS-2 expression in Icelandic horse mares in estrus. Endometrial cells in mares and ruminants exhibit increased PTGS-2 mRNA expression prior to luteolysis [20, 34-36]. However, in early pregnancy, PTGS-2 expression is suppressed [20, 35]. Palm et al. [29] described that in mares close to luteolysis there is a positive correlation between the release of PGF $_{2 \alpha}$ and the expression of endometrial PTGS-2. In our study, we took biopsies from mares in estrus and the intensity of PTGS-2 expression was found in most cases to be low. Troedsson et al. [37] observed that enzymes and $\mathrm{PGF}_{2 \alpha}$, released by PMNs during the process of phagocytosis contribute to increased uterine contractions $4-12 \mathrm{~h}$ after artificial insemination (AI) in mares. Keith et al. [36] observed that the expression of PTGS-2 mRNA decreased 3.7-fold in oxytocin-treated mares compared with control mares, and the mares treated with oxytocin had decreased en- dometrial PTGS-2 immunoexpression on Day 14 postovulation. They explained that the ability of oxytocin to generate prostaglandin release is further regulated by the concentration of uterine oxytocin receptors throughout the estrous cycle [36]. Madill et al. [38] reported that the immediate uterine contractions after natural mating or AI are most likely initiated by mechanical stimulation of the vagina and cervix, which mediate neurogenic oxytocin release. Boerboom et al. [20] showed that the levels of PTGS-2 were 4.5-fold higher in the surface epithelium on Day 15 in nonpregnant mares than in pregnant mares. The PTGS-2 expression in biopsies obtained from our mares was mostly weak and only in a few cases was it moderate to strong. We observed a correlation between PTGS-2 expression in the surface epithelium and PMNs infiltration in the endometrium, as well as with the Kenney and Doig [12] grading system. We found a dependence between PTGS-2 expression in the glandular epithelium and the biopsy score according to Kenney and Doig [12]. However, we did not find a relationship between the PMNs infiltration in the endometrium and PTGS-2 expression in the glandular epithelium.

Aresu et al. [15] demonstrated a relationship between animal age and the grade of endometrosis. Ricketts and Alonso [25] reported that the degree of endometrosis in mares increases with age, but there was no association with the number of foalings. We observed no significant differences between fibronectin expression in the stroma and PTGS-2 expression in the surface epithelium and (i) age of the mares and (ii) the reproductive status of the mares.

Additionally, Aresu et al. [15] pointed out that results obtained from biopsies and entire-wall samples coincide. In our study, we took two endometrial biopsies from different locations in the uterus (the base of the left and right uterine horns) and there were statistically significant differences in the Kenney and Doig [12] 
grading system, fibronectin expression in stroma and PTGS-2 expression in the surface epithelium. Fiala et al. [22] in a study performed after slaughter concluded that only one biopsy is not enough to verify the quantity of degenerative changes in the endometrium. Overbeck et al. [23], in a post mortem study using cytological brushes and endometrial biopsies, observed that the process of inflammation is not the same in different uterine locations. Moreover, results of the present study, in agreement with the literature [22, 23], demonstrate that a single biopsy is insufficient for diagnosing endometritis.

\section{Conclusions}

This study found significant differences in results obtained from two endometrial biopsies collected from one mare between the Kenney and Doig [12] grading system, fibronectin and PTGS-2 immunoreactivity, demonstrating that taking more than one biopsy sample is necessary for better diagnosing infertility in mares. The relationship between fibronectin and PTGS-2 expression and PMNs infiltration in the endometrium, as well as an adequate biopsy score according to Kenney and Doig [12] encourages the use of immunohistochemistry as an additional diagnostic tool for endometritis and endometrosis in mares.

\section{Acknowledgements}

Project supported by Wroclaw Centre of Biotechnology, program The Leading National Research Centre (KNOW) for years 2014-2018. The authors are indebted to an experienced native English speaker Dr. Barry Bavister for professional scientific and language editing of this manuscript.

\section{Authors' contribution}

All authors were involved in discussing and interpreting the data described in this study. MS contributed to sample collection, cytological analysis, analysis of the results and writing the manuscript. MN contributed by histopathological examination. HR and KW contributed analysis of the results. RK contributed in conceiving the study, sample collection, cytological analysis, analysis of the results and writing the manuscript. All authors critically read and approved the final version of the manuscript.

\section{Competing interest}

This work has not been published previously and it is not under consideration for publication.

\section{References}

1. Walter I, Handler J, Reifinger M, et al. Association of endometriosis in horses with differentiation of periglandular myofibroblasts and changes of extracellular matrix proteins. Reproduction. 2001; 121(4): 581-586, doi: 10.1530/rep.0.1210581, indexed in Pubmed: 11277878.

2. Liu IKM, Troedsson MHT. The diagnosis and treatment of endometritis in the mare: yesterday and today. Theriogenology. 2008; 70(3): 415-420, doi: 10.1016/j.theriogenology.2008.05.040, indexed in Pubmed: 18513792.

3. Traub-Dargatz JL, Salman MD, Voss JL. Medical problems of adult horses, as ranked by equine practitioners. J Am Vet Med Assoc. 1991; 198(10): 1745-1747, indexed in Pubmed: 2071472.

4. Schlafer DH. Equine endometrial biopsy: enhancement of clinical value by more extensive histopathology and application of new diagnostic techniques? Theriogenology. 2007; 68(3): 413-422, doi: 10.1016/j.theriogenology.2007.04.040, indexed in Pubmed: 17560641.

5. Schoon HA, Schoon D, Klug E. The endometrial biopsy in the mare with regard to clinical correlations. Pferdeheilkunde Equine Medicine. 1997; 13(5): 453-464, doi: 10.21836/ pem19970506.

6. LeBlanc MM, Causey RC. Clinical and subclinical endometritis in the mare: both threats to fertility. Reprod Domest Anim. 2009; 44(Suppl 3): 10-22, doi: 10.1111/j.14390531.2009.01485.x, indexed in Pubmed: 19660076.

7. Ricketts SW, Barrelet A. A retrospective review of the histopathological features seen in a series of 4241 endometrial biopsy samples collected from UK Thoroughbred mares over a 25 yearperiod. Pferdeheilkunde Equine Medicine. 1997; 13(5): 525-530, doi: 10.21836/pem19970517.

8. Snider TA, Sepoy C, Holyoak GR. Equine endometrial biopsy reviewed: Observation, interpretation, and application of histopathologic data. Theriogenology. 2011; 75(9): 1567-1581, doi: 10.1016/j.theriogenology.2010.12.013.

9. Buczkowska J, Kozdrowski R, Nowak M, et al. Comparison of the biopsy and cytobrush techniques for diagnosis of subclinical endometritis in mares. Reprod Biol Endocrinol. 2014; 12: 27, doi: 10.1186/1477-7827-12-27, indexed in Pubmed: 24708825 .

10. Kozdrowski R, Sikora M, Buczkowska J, et al. Effects of cycle stage and sampling procedure on interpretation of endometrial cytology in mares. Anim Reprod Sci. 2015; 154: 56-62, doi: 10.1016/j.anireprosci.2015.01.009, indexed in Pubmed: 25660623.

11. Nielsen JM. Endometritis in the mare: a diagnostic study comparing cultures from swab and biopsy. Theriogenology. 2005; 64(3): 510-518, doi: 10.1016/j.theriogenology.2005.05.034, indexed in Pubmed: 15978661.

12. Kenney RM, Doig PA. Equine endometrial biopsy. In: Marrow D. ed. Current therapy in theriogenology. WB Sounders, Philadelphia 1986: 723-729.

13. Walter I, Handler J, Miller I, et al. Matrix metalloproteinase 2 (MMP-2) and tissue transglutaminase (TG 2) are expressed in periglandular fibrosis in horse mares with endometrosis. Histol Histopathol. 2005; 20(4): 1105-1113, doi: 10.14670/ HH-20.1105, indexed in Pubmed: 16136493.

14. Hoffmann C, Ellenberger C, Mattos R, et al. The equine endometrosis: New insights into the pathogenesis. Animal Reproduction Science. 2009; 111(2-4): 261-278, doi: 10.1016/j. anireprosci.2008.03.019.

15. Aresu L, Benali S, Giannuzzi D, et al. The role of inflammation and matrix metalloproteinases in equine endometriosis. J Vet Sci. 2012; 13(2): 171, doi: 10.4142/jvs.2012.13.2.171. 
16. Krzyzanowska- Golab D, Lemańska-Perek A and Kątnik-Prastowska I. Fibronektyna jako aktywny składnik macierzy pozakomórkowej. Postepy Hig Med Dosw. 2007; 61: 655-663.

17. Iwahashi M, Muragaki Y, Ooshima A, et al. Alterations in distribution and composition of the extracellular matrix during decidualization of the human endometrium. J Reprod Fertil. 1996; 108(1): 147-155, doi: 10.1530/jrf.0.1080147, indexed in Pubmed: 8958841.

18. Kaidi R, Brown P, David J, et al. Uterine collagen during involution in cattle. Matrix. 1991; 11(2): 101-107, doi: 10.1016/ s0934-8832(11)80213-1.

19. Boos A. Immunohistochemical demonstration of collagen types I, III, IV, V and VI in the bovine endometrium during estrus cycle and after superovulation. Anatomia Histologia Embryologia. 1994; 23: 64.

20. Boerboom D, Brown KA, Vaillancourt D, et al. Expression of key prostaglandin synthases in equine endometrium during late diestrus and early pregnancy. Biol Reprod. 2004; 70(2): 391-399, doi: 10.1095/biolreprod.103.020800, indexed in $\mathrm{Pu}-$ bmed: 14561653.

21. Ma W, Quirion R. Up-regulation of interleukin-6 induced by prostaglandin $\mathrm{E}$ from invading macrophages following nerve injury: an in vivo and in vitro study. J Neurochem. 2005; 93(3): 664-673, doi: 10.1111/j.1471-4159.2005.03050.x, indexed in Pubmed: 15836625.

22. Fiala SM, Esmeraldino A, Jobim MIM, et al. Endometrial fibrotic changes. Is one biopsy enough to diagnose degenerative changes? Anim Reprod Sci. 2010; 121(Suppl): 89-90, doi: 10.1016/j.anireprosci.2010.04.133.

23. Overbeck W, Jäger K, Schoon HA, et al. Comparison of cytological and histological examinations in different locations of the equine uterus-an in vitro study. Theriogenology. 2013; 79(9): 1262-1268, doi: 10.1016/j.theriogenology.2013.02.007, indexed in Pubmed: 23601551.

24. Sikora M, Król J, Nowak M, et al. The usefulness of uterine lavage and acute phase protein levels as a diagnostic tool for subclinical endometritis in Icelandic mares. Acta Vet Scand. 2016; 58(1): 50, doi: 10.1186/s13028-016-0233-4, indexed in Pubmed: 27604098.

25. Ricketts SW, Alonso S. Assessment of the breeding prognosis of mares using paired endometrial biopsy techniques. Equine Vet J. 1991; 23(3): 185-188, doi: 10.1111/j.2042-3306.1991. tb02751.x.

26. LeBlanc MM, Magsig J, Stromberg AJ. Use of a low-volume uterine flush for diagnosing endometritis in chronically infertile mares. Theriogenology. 2007; 68(3): 403-412, doi: 10.1016/j.theriogenology.2007.04.038, indexed in Pubmed: 17543379

27. Christoffersen M, Brandis L, Samuelsson J, et al. Diagnostic double-guarded low-volume uterine lavage in mares. Therio- genology. 2015; 83(2): 222-227, doi: 10.1016/j.theriogenology.2014.09.008.

28. Meuten DJ, Moore FM, George JW. Mitotic count and the field of view area: time to standardize. Vet Pathol. 2016; 53(1): 7-9, doi: 10.1177/0300985815593349, indexed in Pubmed: 26712813.

29. Palm F, Walter I, Budik S, et al. Influence of different semen extenders and seminal plasma on PMN migration and on expression of IL-1beta, IL-6, TNF-alpha and COX-2 mRNA in the equine endometrium. Theriogenology. 2008; 70(5): 843-851, doi: 10.1016/j.theriogenology.2008.04.054, indexed in Pubmed: 18584861.

30. Schoon HA, Schoon D. The Category I mare (Kenney and Doig 1986): Expected foaling rate $80-90 \%$ - fact or fiction? Pferdeheilkunde. 2003; 19: 698-701, doi: 10.21836/ PEM20030626.

31. Sappino AP, Schürch W, Gabbiani G. Differentiation repertoire of fibroblastic cells: expression of cytoskeletal proteins as marker of phenotypic modulations. Lab Invest. 1990; 63(2): 144-161, indexed in Pubmed: 2116562.

32. Schmitt-Gräff A, Desmoulière A, Gabbiani G. Heterogeneity of myofibroblast phenotypic features: an example of fibroblastic cell plasticity. Virchows Arch. 1994; 425(1): 3-24, doi: 10.1007/bf00193944, indexed in Pubmed: 7921410.

33. Mansour GD, Henry M, Ferreira A. Immunohistochemical study of equine endometrial extracellular matrix during the oestrous cycle. J Comp Path. 2003; 129(4): 316-319, doi: 10.1016/s0021-9975(03)00048-3.

34. Arosh JA, Parent J, Chapdelaine P, et al. Expression of cyclooxygenases 1 and 2 and prostaglandin $E$ synthase in bovine endometrial tissue during the estrous cycle. Biol Reprod. 2002; 67(1): 161-169, doi: 10.1095/biolreprod67.1.161, indexed in Pubmed: 12080013.

35. Atli M, Kurar E, Kayis S, et al. Evaluation of genes involved in prostaglandin action in equine endometrium during estrous cycle and early pregnancy. Animal Reprod Sci. 2010; 122(1-2): 124-132, doi: 10.1016/j.anireprosci.2010.08.007.

36. Keith L, Ball BA, Scoggin K, et al. Diestrus administration of oxytocin prolongs luteal maintenance and reduces plasma PGFM concentrations and endometrial COX-2 expression in mares. Theriogenology. 2013; 79(4): 616-624, doi: 10.1016/j. theriogenology.2012.11.015, indexed in Pubmed: 23260864.

37. Troedsson M, Liu I, Crabo BG. Sperm transport and survival in the mare. Theriogenology. 1998; 49(5): 905-915, doi: 10.1016/s0093-691x(98)00040-5.

38. Madill S, Troedsson MH, Alexander SL, et al. Simultaneous recording of pituitary oxytocin secretion and myometrial activity in oestrous mares exposed to various breeding stimuli. J Reprod Fertil Suppl. 2000(56): 351-361, indexed in Pubmed: 20681147. 
